\title{
Interaction structures in the psychodynamic psychotherapy of a patient with chronic diseases and somatic symptoms
}

\author{
Estruturas de interação na psicoterapia psicodinâmica de uma paciente com \\ doenças crônicas e sintomas somáticos
}

\author{
Pricilla Braga Laskoski, ${ }^{1}$ (D) Simone Hauck, ${ }^{1,2}$ Stefania Pigatto Teche, ${ }^{1,2}$ (D) Carolina Stopinski Padoan, ${ }^{1}$ \\ Alcina Juliana Soares Barros, ${ }^{1}$ Fernanda Barcellos Serralta, ${ }^{3}$ (D) Cláudio Laks Eizirik ${ }^{1,4}$
}

\begin{abstract}
Objective: This study aimed to identify and analyze the interaction structures (ISs) (patterns of reciprocal interaction between the patient-therapist dyad) that characterize the process of a successful long-term psychodynamic psychotherapy (28 months) of a patient with chronic diseases (lupus and fibromyalgia) and somatic symptoms.

Methods: The 113 sessions were videotaped and analyzed alternately $(n=60)$ by independent judges using the Psychotherapy Process Q-Set. Inter-rater reliability ranged from 0.60 to 0.90 , with a mean of $r=0.71$ (Pearson's correlation). Through a principal component exploratory factor analysis, four ISs were identified.

Results: The patterns of interaction between patient and therapist showed clinical validity (i.e., they were easily interpretable in the context of the case under study). The ISs were non-linear and more or less prominent across different treatment sessions and stages. Some ISs were similar to those in other studies, and others were probably unique to the present process. In addition, some ISs were independent, whereas others were interrelated over time.

Conclusion: Process studies, such as the present one, seek to address questions about the characteristics of the interaction between patient and therapist as well as to identify particular patterns of interaction that are most prominent with a specific patient at a specific condition or time. Therefore, these studies can provide some support in establishing knowledge for clinical practice, assisting in the training of therapists, as well as in the elaboration of general guidelines for the technical management of patients with specific characteristics.

Keywords: Psychodynamic psychotherapy, process research, interaction structures, psychotherapeutic process.
\end{abstract}

\begin{abstract}
Resumo
Objetivo: Este estudo objetivou identificar e analisar as estruturas de interação (interaction structures [ISs]) (padrões de interação recíproca entre a dupla paciente-terapeuta) que caracterizam o processo de uma psicoterapia psicodinâmica de longa duração (28 meses) de uma paciente com doenças crônicas (lúpus e fibromialgia) e sintomas somáticos.

Métodos: As 113 sessões foram filmadas e analisadas alternadamente $(n=60)$ por juízes independentes usando o Psychotherapy Process Q-Set. A confiabilidade entre avaliadores variou de 0.60 a 0.90 , com média de $r=0.71$ (correlação de Pearson). Por meio de uma análise fatorial exploratória do componente principal, foram identificadas quatro ISs.

Resultados: Os padrões de interação entre paciente e terapeuta mostraram validade clínica (ou seja, foram facilmente interpretáveis no contexto do caso em estudo). As ISs foram não lineares e mais ou menos proeminentes em diferentes sessões e etapas do tratamento. Algumas ISs foram semelhantes às de outros estudos, e outras provavelmente foram exclusivas do presente processo. Além disso, algumas ISs eram independentes, enquanto outras estavam inter-relacionadas ao longo do tempo. Conclusão: Estudos de processo como o presente procuram abordar questões sobre as características da interação entre paciente e terapeuta, bem como identificar padrões particulares de interação que são mais proeminentes com um determinado paciente em condições ou momentos específicos. Portanto, esses estudos podem fornecer suporte ao estabelecimento de conhecimentos para a prática clínica, auxiliando na formação de terapeutas, bem como na elaboração de diretrizes gerais para o manejo técnico de pacientes com características específicas. Descritores: Psicoterapia psicodinâmica, pesquisa de processo, estruturas de interação, processo psicoterapêutico.
\end{abstract}

\footnotetext{
${ }_{1}$ Programa de Pós-Graduação em Psiquiatria e Ciências do Comportamento, Universidade Federal do Rio Grande do Sul (UFRGS), Porto Alegre, RS, Brazil. 2 Hospital de Clínicas de Porto Alegre, Porto Alegre, RS, Brazil. ${ }^{3}$ Programa de Pós-Graduação em Psicologia Clínica, Universidade do Vale do Rio dos Sinos (UNISINOS), São Leopoldo, RS, Brazil. ${ }^{4}$ Sociedade Psicanalítica de Porto Alegre, Porto Alegre, RS, Brazil.

This study was previously presented and awarded first place in the Professor David E. Zimerman Award, Psychotherapy category, during XIII Congresso Gaúcho de Psiquiatria, held in Bento Gonçalves, RS, Brazil, in August 17-19 2017.

Submitted Nov 24 2017, accepted for publication Aug 212018.

Suggested citation: Laskoski PB, Hauck S, Teche SP, Padoan CS, Barros AJS, Serralta FB, et al. Interaction structures in the psychodynamic psychotherapy of a patient with chronic diseases and somatic symptoms. Trends Psychiatry Psychother. 2019;41(2):128-135. http://dx.doi.org/10.1590/2237-6089-2017-0146
} 


\section{Introduction}

Over the last few decades, significant advances in psychotherapy research have been made, particularly in the field of outcome research. Many studies have shown consistent evidence regarding the efficacy and effectiveness of psychodynamic psychotherapy (PDT) in a wide range of disorders. ${ }^{1-3}$ Although psychodynamic treatments have already been considered to lead to significant therapeutic progress, understanding the aspects that contribute to psychological change during psychotherapy remains challenging. ${ }^{4,5}$

Despite changes in the conceptualization of the therapeutic process over time, two principal chains of thought have been identified on the basis of therapeutic action: on the one hand, a centrality of interpretations and specific techniques promoting change (i.e., "specific ingredients"); on the other hand, a focus on interpersonal interaction as a preponderant promoter of positive outcomes (i.e., aspects described as "common factors," such as empathy and therapeutic alliance). Moreover, the last few decades have seen a stronger intersubjective orientation occurring within psychoanalytic thinking, creating space for the therapist's subjectivity and focusing not only on the patient's mind but also on vicissitudes of the interaction between patient and therapist. ${ }^{6}$

Thereby, Enrico Jones ${ }^{7}$ proposed the existence of patterns of reciprocal interaction between patient and therapist throughout a therapeutic process, termed as interaction structures (ISs) (pp. $x v, 16)$, which are manifested as a part of the transferencecountertransference matrix. ${ }^{7}$ From this, he developed a theory of therapeutic action (from psychoanalysis and PDT) that combines the effects of both insight and patient-therapist relationship on treatment outcomes, either facilitating or hindering therapeutic progress. In other words, he proposed that neither insight nor relationship alone will lead to changes in PDT. Accordingly, the IS theory of therapeutic action has been consistent with other findings and research, suggesting that common and unique factors most likely work symbiotically (and sometimes parasitically) with one another and are likely to be present and potentially relevant in any given psychotherapy. ${ }^{8}$

Previous studies have detected ISs between the patient and therapist in different contexts (inpatients and outpatients) and lengths (short- and longterm psychotherapy and psychoanalysis), as well as in children. ${ }^{9-14}$ Single-case designs provide a rich description of processes occurring in each dyad while serving as an important complement to aggregated data in group-level studies. Most importantly, single-case studies have facilitated the ideographic examination of particular processes, evidencing the considerable clinical potential of this research approach.

\section{PDT and patients with somatic symptom disorder}

There exists a substantial body of evidence on the efficacy of PDT in the treatment of somatoform disorders, referred to as somatic symptom disorder in the 5th edition of the Diagnostic and Statistical Manual of Mental Disorders (DSM-5). ${ }^{15}$ Evidence from randomized controlled trials (RCTs) is available for irritable bowel syndrome, functional dyspepsia and somatoform pain disorder. Accordingly, each of these RCTs found PDT to be superior to the usual treatment or supportive therapy. Moreover, results from a meta-analysis showed PDT to be efficacious in patients with somatic symptom disorder. ${ }^{2}$ However, the field of process research involving such patients has been relatively incipient. Somatic symptom disorder has a prevalence of $10-20 \%$ and is considered difficult to treat by clinicians, ${ }^{16}$ who often report difficult transference-countertransference patterns with such patients. ${ }^{17}$ This group of patients usually present operative functioning, which is also accompanied by a strong cathexis of the physical senses, with patients being able to describe at length and in detail what they have perceived. ${ }^{18,19}$ These characteristics tend to make it difficult for such patients to enter psychoanalyticoriented treatments. Instead of pursuing links between complaints and life events or inner conflicts, patients may end up feeling misunderstood. In this sense, it is expected that a patient with those characteristics will present narratives that avoid emotional contact, maintaining their focus on the somatic complaints. Thus, examining the ISs established during the treatment of such patients can be quite useful.

Therefore, the present study aimed to identify and analyze the ISs (i.e., patterns of reciprocal interaction) that characterize the treatment of a patient with somatic symptom disorder and chronic diseases in a naturalistic setting. We also investigated whether there was any correlation between the identified ISs throughout the treatment. This case is part of a larger project that compiles systematic case studies of patients with personality disorders. The current case was selected for convenience given that it involved a patient with more advanced age (in relation to the others) and somatic symptoms. Considering the few studies on PDT process outcomes involving a patient with the aforementioned characteristics, the present study was delineated. Our main hypothesis was that patterns of reciprocal interactions existed between the patient and therapist and that they could be captured by an empirical methodology such as IS. 


\section{Methods}

\section{Participants \\ Client}

Doris (name and identifying details have been changed to protect the privacy of the patient), a divorced Caucasian with three children, was 67 years old when her treatment initiated. As a patient, she was being treated in a clinical outpatient setting. She sought therapy due to chronic health problems (lupus, fibromyalgia and hypertension) and considerable psychological distress resulting from the physical limitations associated with such diseases.

\section{Therapist}

The psychotherapist was a female clinical psychologist with 10 years of experience and training in psychoanalytic psychotherapy. She described herself as being psychoanalytically oriented.

\section{Treatment}

Before Doris was referred to the therapist, an interview was conducted after the client signed a consent form to participate in the study. She received individual treatment comprising non-manualized psychodynamic therapy once a week. The treatment setting was an outpatient clinic consisting of psychotherapists with a psychoanalytic background based on Freud and his followers, in a city within a Latin American country. After 28 months (113 sessions), the therapist moved to a new city, and thus referred Doris to a new therapist. In less than 2 months (7 sessions) with the new therapist, Doris decided to conclude her therapy. The entire treatment lasted 30 months and reached 120 weekly sessions of 50 min each. All sessions were videotaped with both the patient's and therapist's consent. Given that ISs are related to a specific patient-therapist dyad, the sessions held with the second therapist were not considered for the present analysis.

\section{Diagnosis}

The initial clinical diagnosis according to DMS-5 criteria was somatic symptom disorder (concrete and operative functioning mode) and cluster C traits.

\section{Measures}

Psychotherapy Process Q-Set (PQS) 20

The PQS is a 100-item rating instrument designed to describe and classify treatment processes in a form that is suitable for quantitative analysis. Its items comprise aspects related to the interaction or atmosphere during the encounter, patient's attitudes and behaviors and therapist's actions and attitudes that are characteristic of various schools of therapy, including psychodynamic (e.g., focusing on the unconscious), cognitive behavioral (e.g., focusing on belief systems) and interpersonal (e.g., focusing on relationships) therapies. It also includes items addressing therapeutic processes that are common to all or most schools of therapy (e.g., empathy). After watching the recording of a therapy session, independent evaluators are required to organize the items into nine categories using a forced-choice procedure ranging from most uncharacteristic (category 1 ) to most characteristic (category 9) of the session being rated. Items were evaluated among themselves (ipsatively) rather than with reference to an objective standard (normatively). This ipsative procedure yields a normal distribution that characterizes both the high and low ends of a construct. The PQS has shown good inter-rater reliability, construct validity and discriminant validity according to prior research. ${ }^{9}$ Moreover, the Brazilian Portuguese version of the $\mathrm{PQS}^{21}$ has shown semantic equivalence with the original $\mathrm{PQS}$ and comparable inter-rater reliability between trained evaluators. ${ }^{22}$

\section{Outcome Questionnaire $(O Q-45)^{23}$}

The OQ-45 is a self-report instrument comprising 45 items that are grouped into three scales, namely symptom distress ( $S D=25$ items), interpersonal relations ( $\mathrm{IR}=$ 11 items) and social role ( $\mathrm{SR}=9$ items), which add up to provide a total score (OQ-45 total score). Responses are provided using a 5-point Likert-type scale ranging from never ( 0 points) to almost always ( 4 points), with the total score possibly ranging from 0 to 180 points. A high score suggests that the client is admitting to several symptoms of distress (primarily anxiety, depression, somatic problems and stress), indicating increased disturbance. Scores of 63 or more indicate symptoms of clinical significance (dysfunctionality/functionality). Moreover, the OQ-45 is able to determine not only recovery (scores in the range of community norms) but also clinically reliable changes and deterioration, the latter being defined as a 14-point or greater increase in the total score. This instrument has also been normalized for individuals aged between 18 and 80 years, with no correlation found between test score and age. ${ }^{24}$ The OQ45 , which has been translated and contextually adapted to the Brazilian culture based on the original and Portuguese versions, ${ }^{25}$ has been proven to be a suitable measurement tool for the Brazilian population. ${ }^{26}$

\section{Procedure}

Therapy

This study was approved by the ethics committee of the Universidade do Vale do Rio dos Sinos (protocol $137 / 2011$ ). The patient filled out the OQ-45 during the 
first session, every month or after every fourth session, and finally at the 3-month follow-up. The therapist was an experienced psychoanalytic psychotherapist who planned the treatment to guide insight and increase reflexive ability. Moreover, $\mathrm{PQS}$ ratings were correlated with the ideal PDT model (obtained from PQS items) and showed significant correlations with most sessions in the present study (to be published elsewhere). The patient did not attend six sessions (sessions 31, 63, 74, 78, 88 and 104). Even though each session was videotaped with both the patient's and therapist's consent, videotapes for three sessions (sessions 24, 57 and 68) were unavailable for analysis due to equipment failure.

\section{$P Q S$ rating procedure}

Two independent trained judges rated randomly drawn videotapes of every other session (a total of 60 sessions were assessed). The pool of raters comprised nine psychologists and four psychiatrists: seven doctorallevel clinicians and six master-level clinicians with a mean clinical experience of 6 years. All judges had undergone psychodynamic or cognitive behavioral psychotherapy training. They were blinded to the result of treatment, as well as to the identity and ratings of other evaluators. When the reliability between any pair of evaluators was below 0.60 , an additional evaluator rated the session. Inter-rater reliability of the PQS ratings of Doris' treatment ranged from 0.60 to 0.90 , with a mean of $r=$ 0.71 (Pearson's correlation). PQS ratings from evaluator pairs were averaged to obtain composite scores.

\section{Data analysis}

ISs in Doris' therapy were identified by subjecting all 100 PQS items for each of the rated sessions ( $\mathrm{N}=$ $60)$ to principal component exploratory factor analysis with varimax rotation. To index the internal consistency of items comprising the factor, alpha reliabilities were calculated for each factor. Factor scores were calculated for each factor in each session by averaging the ratings of the most strongly loading PQS items. The rationale for the analysis can be summarized as follows: in the examination of a single-case therapeutic process, multiple sessions of the case are systematically examined with repeated applications of the same Q-set of variables (the $100 \mathrm{PQS}$ items). Thus, for each session, all 100 items are ranked in a particular order using the average individual orderings of the two independent evaluators. The set of sessions is called the P-set, whereas the correlation matrix (P-set vs. Q-set) identifies the processes that stand out positively or negatively in the sessions. Factor analysis aims to identify natural groupings of variables for the patient and therapist during therapy. These groupings or factors represent ISs. ${ }^{14}$ Sessions with higher scores were reviewed to ensure clinical validity. To verify whether one structure predicted the other, we proceeded with cross-correlation analysis in an exploratory manner, considering all intervals up to 15 Lags.

\section{Results}

\section{Assessment of treatment outcome}

Figure 1 demonstrates the behavior of the OQ45 scores and its three subscales (symptom distress, interpersonal relations and social role) throughout the treatment and follow-up period. Each dashed line represents the cut-off point proposed by the instrument, indicating symptoms of clinical significance. Although Doris' scores varied considerably throughout her treatment, particularly in relation to the OQ- 45 total score and the symptom distress and social role subscales, a significant decrease was observed overall. This suggests an improvement in such domains, indicating a change from dysfunctionality to functionality when comparing evaluations performed at the beginning and at followup. However, the interpersonal relations subscale always scored below the cut-off point, indicating no dysfunctionality in this domain.

\section{Interaction structures (ISs)}

Factor analysis yielded four conceptually interpretable ISs, which were labelled as follows: IS 1) Exploring troublesome affects; IS 2) Building and enhancing therapeutic alliance; IS 3) Therapeutic relationship - prelude of the end; and IS 4) Coping with physical symptoms. The aforementioned ISs accounted for over $30.3 \%$ of the total variance. Table S1 (onlineonly supplementary material) shows PQS item factor loadings for the four ISs. Only IS 2 became less characteristic during treatment $(r=-0.56, \mathrm{p}<0.001)$, whereas ISs 1,3 and 4 remained constant over time.

\section{IS 1) Exploring troublesome affects (Cronbach's $a=0.88$ )}

This IS is characterized by the patient's experience of troublesome affects, such as anxiety, tension, sadness, shame and guilt. The therapist explores such negative affects and questions the patient's perspective in a more serious mood. Doris shows limited future expectations in relation to her treatment. In this sense, the patient seems ambivalent about therapy or unwilling to tolerate the emotional hardships that therapy might entail. Nevertheless, the patient keeps working collaboratively. This IS, which comprised 19 items with factorial loads between -0.405 and 0.837 , accounted for $10.73 \%$ of the variance in this process. 
IS 2) Building and enhancing therapeutic alliance

(Cronbach's $a=0.87$ )

This IS demonstrates an empathic and confident therapist seeking to facilitate patient speech and clear communication. Moreover, the therapist condescends to or patronizes the patient and intervenes to help the patient avoid or suppress disturbing ideas or feelings. The patient expresses herself in a clear fashion and understands the nature of the therapy and what is expected. In addition, the patient feels understood by the therapist and is introspective. The dialogue is centered on cognitive themes, and the dyad seems to be working in a less troublesome way. This IS, which comprised 19 items with factorial loads between -0.402 and 0.704 , accounted for $9.32 \%$ of the variance in this process and became less characteristic throughout the 28 months of treatment $(r=-0.56 ; \mathrm{p}<0.001)$.

IS 3) Therapeutic relationship - prelude of the end (Cronbach's $a=0.76$ )

This IS is characterized by the emphasis placed on the therapeutic relationship and the therapist's attempt to use it as a vehicle to potentiate therapeutic work. Termination of therapy and the patient's self-image are also emphasized during the sessions. This affects the patient who seeks the therapist's approval (behaving in a manner that is apparently designed to either make the therapist like her or gain attention or reassurance). Doris is concerned with what the therapist might think of her. The patient seeks greater intimacy with the therapist and/or attempts to gain knowledge of the therapist's personal life. This IS, which comprised 10 items with factorial loads between -0.421 and 0.735 , accounted for $5.50 \%$ of the variance in this process.

IS 4) Coping with physical symptoms (Cronbach's $a=0.73$ )

This IS is characterized by the therapist's supportive stance and direct reassurance in relation to the patient's current physical symptoms and health limitations. This IS, which comprised eight items with factorial loads between -0.534 and 0.518 , accounted for $4.76 \%$ of the variance in this process.

Regarding cross-correlation analysis, Figure 2 shows the correlations between pairs of interaction structures. Accordingly, only the combination of IS 2 and IS 3 showed a significant negative correlation at Lag -13 ( $r$ $=-0.322 ; p=0.02)$. Although a negative correlation could also be observed at Lag -10 , the $p$-value was not considered significant in accordance with the established convention of $0.05(r=-0.248 ; p=0.06)-p$-values between 0.05 and 0.10 represent a trend. The same was found for the combination of IS 2 and IS 4 at Lag $-5(r=-0.245 ; \mathrm{p}=0.06)$.

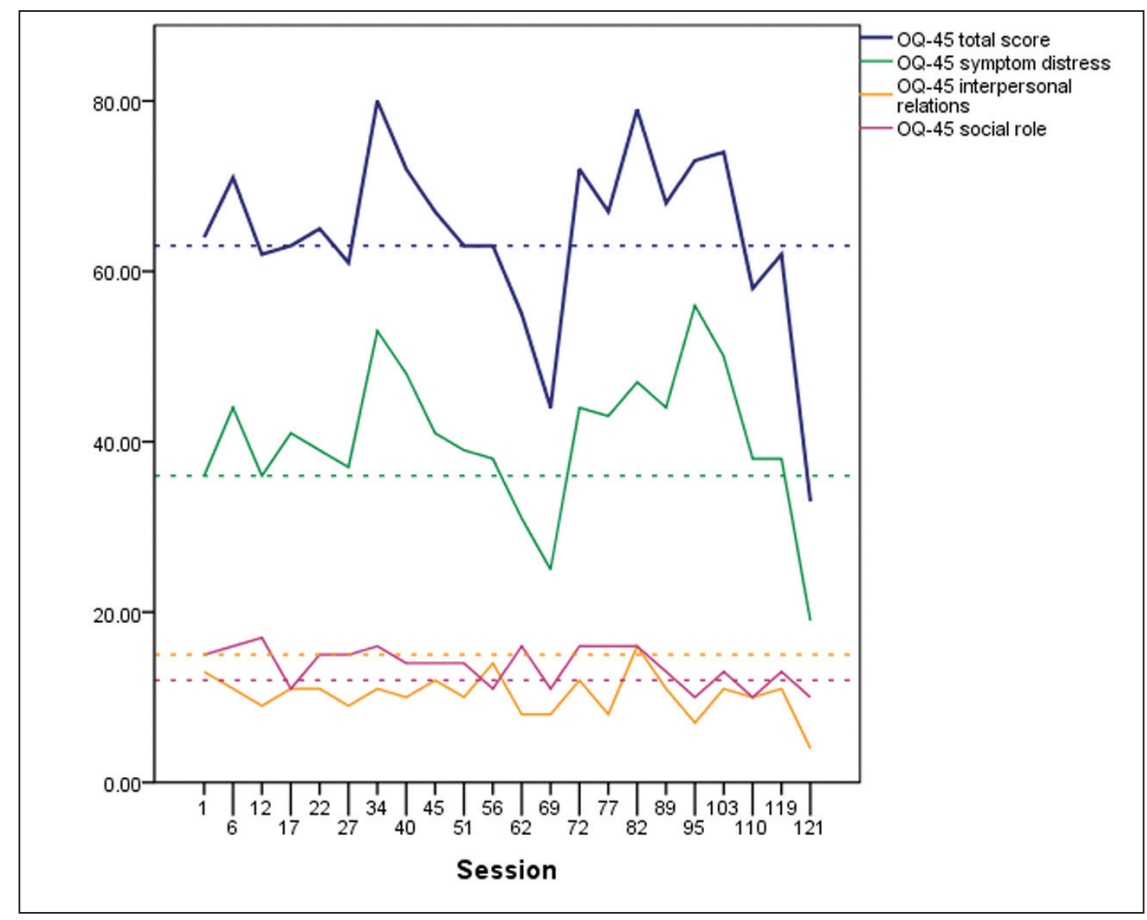

Figure 1 - Outcome Questionnaire (OQ-45) scores throughout treatment and at follow-up 


\section{Discussion}

The present study identified four ISs between a patient with chronic diseases, cluster $\mathrm{C}$ traits and somatic symptom disorder and an experienced therapist during treatment. It also verified that some detected ISs were independent, whereas others were interrelated over time. Moreover, the patterns of interaction between the patient and therapist displayed clinical validity (i.e., they were easily interpretable in the context of the case under study). ISs remained non-linear and more or less prominent in different sessions and treatment stages. Furthermore, we found an IS focusing on affect (IS 1) and another corresponding to the therapeutic alliance (IS 2), findings that are generally consistent with those of other studies. ${ }^{11,14}$ The two aforementioned ISs seem to represent a specific factor of the approach employed and a common factor to all therapies, respectively. In addition, we were able to identify a structure centered on the therapeutic relationship, which can also be interpreted as illustrating an aspect of the technique prescribed by the approach employed. Finally, we detected a structure clearly related to the patient's complaint (somatic issues).
Affect avoidance and difficulty in acknowledging and expressing negative affects are shared characteristics of patients with cluster $\mathrm{C}$ personality disorders (or traits of them) and those with somatic symptom disorder, both of which are important aspects observed in Doris. ${ }^{27}$ In IS 1 (Exploring troublesome affects), we observed that the therapist focused exactly on this issue, i.e., on feelings that are considered wrong, inappropriate or dangerous by the patient. The manner of Doris's reaction is an indication of the sensitivity of this point. She experiences a mental state of negative affects and also seemed to be unwilling to tolerate the emotional hardships that therapy might entail. This possibly illustrates a patient getting in touch with her painful psycho-emotional reality and falling further into depression instead of unloading such feelings into her body. These moments may have enabled the gradual retranslation of physical symptoms separated from inner experience into subjective experience. Shedler ${ }^{28}$ pointed out that seven features reliably distinguish PDT from other therapies. Focus on affect and expression of emotion, as well as exploration of attempts to avoid distressing thoughts and feelings, are two of them. In IS 1 , we observe the therapist actively
IS1 \& IS2

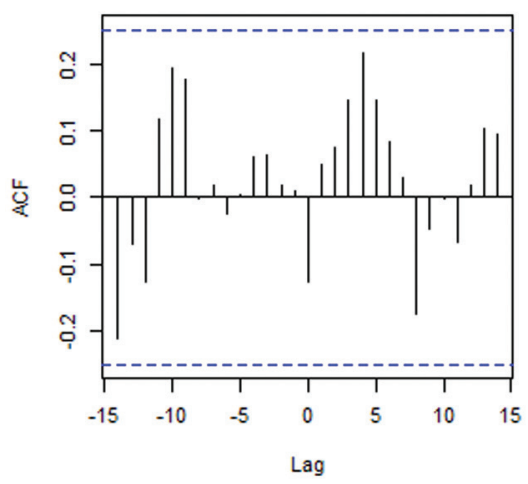

IS2 \& IS3

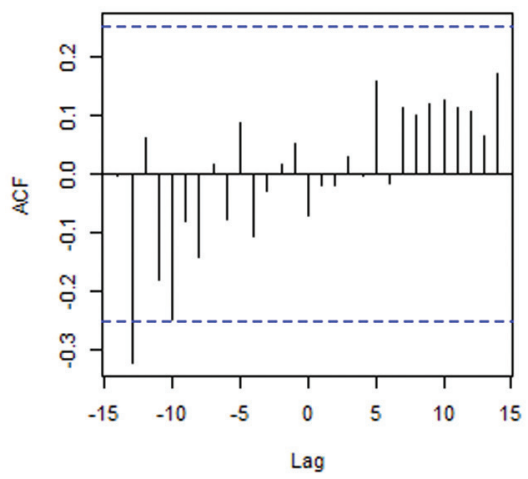

IS1 \& IS3

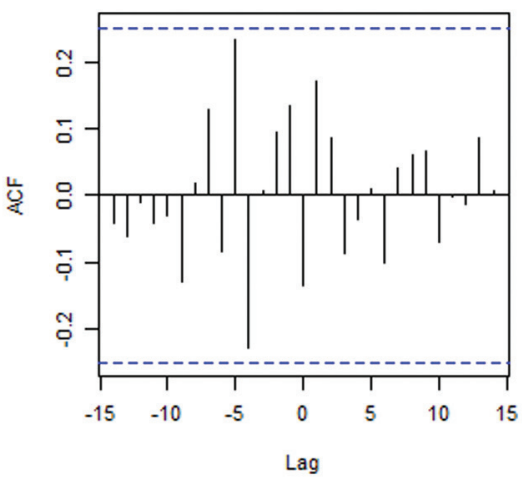

IS2 \& IS4

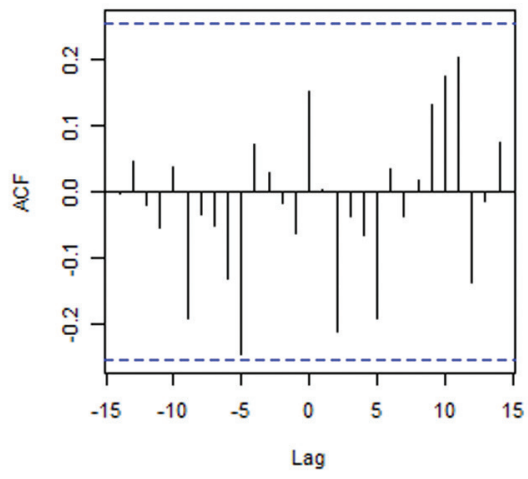

IS1 \& IS4

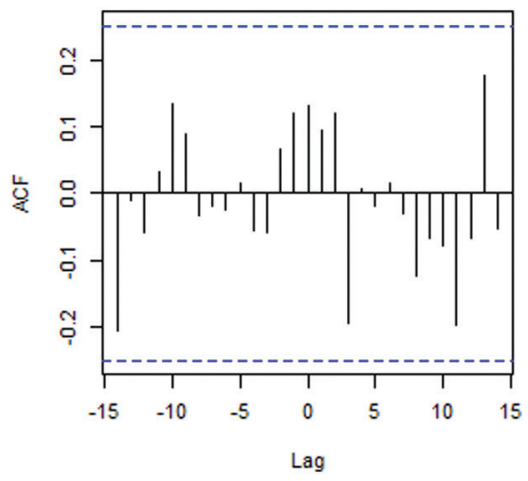

IS3 \& IS4

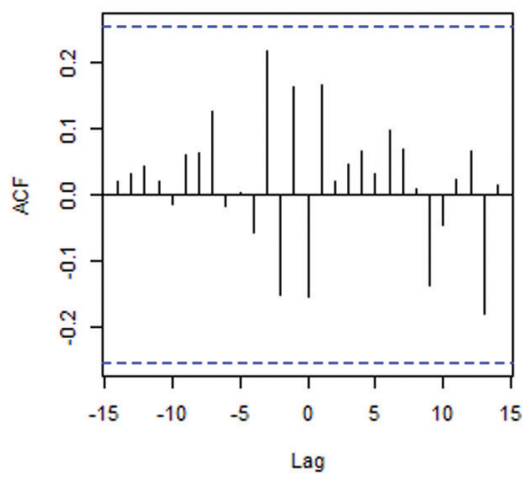

Figure 2 - Correlations between pairs of ISs. ACF = auto correlation function; IS = interaction structure. 
using this line as a therapeutic strategy. In this sense, as expected, such patient's characteristics may contribute to form a pattern of interaction based on negative emotions (IS 1) as well as on physical symptoms and health conditions as observed in IS 4.

Conversely, IS 2 (Building and enhancing therapeutic alliance) illustrates a therapist employing facilitative interventions aimed at establishing a therapeutic alliance with the patient. In other words, one perceives a prominence in the therapist's items, reflecting her investment in strengthening the alliance, while ensuring not to markedly disturb the patient. Distanced from her affects and therefore probably feeling more comfortable, Doris is now able to introspect. Stimulating cognition may have been necessary considering that the patient is physically symptomatic (an approach to separating physical from emotional pain that initially seemed combined). This is the only IS that presented a negative correlation with time. Considering that this structure seems to combine the necessary elements to establish a therapeutic bond, it is expected to be increasingly present in the early stages of treatment. Over time, such a bond is presumed to progressively consolidate, therefore requiring less investment in this regard.

IS 3 was not prominent during the treatment, which is expected for a low-frequency therapy (weekly). However, it reached its highest scores at the end of the process: we can observe the termination of therapy interfering with this process and placing the therapeutic relationship into central focus. In doing so, considering the context of an imminent separation, Doris reacts in a singular way: seeking approval and attention, as well as greater intimacy from her therapist, probably because separation is a central theme in her conflict and personality configuration. The patient also attempts to gain knowledge of the therapist's personal life. We may understand that the therapist's personal life had already been inserted into the process, given that the termination of therapy occurred as a result of the therapist's transfer to a new city. The therapist then attempted to use this situation to potentiate clinical work by drawing connections between the therapeutic relationship and other relationships.

IS 4 illustrates an expected topic considering the characteristics of the patient and the reason why she sought psychotherapy: physical symptoms and health limitations. The therapist tended to adopt a supportive stance, providing reassurance to assist Doris in coping with her condition. This IS showed considerable variation throughout the treatment.

Cross-correlation analysis revealed a significant negative correlation between IS 2 and IS 3 at Lag -13, indicating that a more prominent IS 2 would lead to a less prominent IS 3 in the range of 13 Lags. Actually, once the sessions were analyzed alternately, 13 Lags was determined to have an interval of 26 sessions. In other words, IS 2 predicts IS 326 sessions in advance. To better understand this relationship, we may consider the steps of a dance where one movement will precede another, thus forming a choreography. In this sense, the more the pair dances to a rhythm that illustrates the work associated with building and enhancing the therapeutic alliance, the less rhythmic the following movements will become based on their focus on the therapeutic relationship. In the same way, the lesser the rhythm invested in the therapeutic alliance, the more focused the therapeutic relationship will become during the following movements. Hence, throughout the treatment, working on the therapeutic relationship may have been only necessary when the therapeutic alliance between the pair was weak.

Even though the correlation between IS 2 and IS 3 at Lag -10 failed to reach statistical significance, it indicated a trend. When considered in conjunction with Lag -13 , it suggests the existence of a Lag region (between Lag -10 and Lag -13), thus indicating the need for careful evaluation of this association.

Similarly, cross-correlation analysis provided an almost significant negative correlation between IS 2 and IS 4 at Lag -5 , indicating that a more prominent IS 2 would lead to a less prominent IS 4 in the range of Lag -5 ( 10 sessions). As mentioned before, the $p$-value was not considered significant according to the established convention of 0.05 . However, we believe that a $p$-value of 0.06432 cannot be disregarded, once it indicates a trend. This correlation illustrates a movement similar to that described in the correlation between IS 2 and IS 3: the more the pair dances to a rhythm based on work associated with building and enhancing the therapeutic alliance, the less prominent the following movements will become regarding themes related to somatic symptoms. From this, we may assume that an experience of greater closeness between the pair tends to lead to less prominent physical issues. This seems to be consistent with the characteristics of the patient, in relation to both personality configuration (dependent traits) and somatic symptom disorder.

In summary, this study concludes that ISs, which can be empirically observed using the PQS, make up the psychotherapeutic process. In this case, the best model identified was a composite of four factors, some of which were similar to those in other studies (interactions regarding the therapeutic alliance are quite common), whereas others were probably unique to the process here described. In addition, some ISs were independent, whereas others were 
interrelated over time. Future research should evaluate these structures in relation to the results to determine if and what patterns are related or predict outcome.

Process studies such as the present one seek to address questions regarding the characteristics of the interaction between patient and therapist, as well as what particular patterns of interaction are most prominent with a specific patient at a specific condition or time. Such studies could therefore provide some support in establishing knowledge imperative for clinical practice, thereby assisting in the training of therapists and refinement of general guidelines for the technical management of patients with specific characteristics. In this sense, process research may bridge the gap between researchers and clinicians by providing answers or directions that are highly relevant during practitioner decision-making. ${ }^{29}$

\section{Acknowledgements}

This research was funded by Coordenação de Aperfeiçoamento de Pessoal de Nível Superior (CAPES) and Conselho Nacional de Desenvolvimento Científico e Tecnológico (CNPQ). The funding sources did not play any role in the collection, analysis, interpretation of the data, manuscript writing, or the decision to submit for publication.

\section{Disclosure}

No conflicts of interest declared concerning the publication of this article.

\section{References}

1. Fonagy P. The effectiveness of psychodynamic psychotherapies: An update. World Psychiatry. 2015;14:137-50.

2. Leichsenring $F_{\text {, Luyten }}$, Hilsenroth $M J$, Abbass $A$, Barber JP, Keefe JR, et al. Psychodynamic therapy meets evidence-based medicine: A systematic review using updated criteria. Lancet Psychiatry. 2015;2:648-60.

3. Steinert C, Munder T, Rabung S, Hoyer J, Leichsenring F. Psychodynamic therapy: as efficacious as other empirically supported treatments? A meta-analysis testing equivalence of outcomes. Am J Psychiatry. 2017;174:943-53.

4. Wampold BE. How important are the common factors in psychotherapy? An update. World Psychiatry. 2015;14:270-7.

5. Krause $M$, Altimir C. Introduction: current developments in psychotherapy process research. Estud Psicol. 2016;37:201-25.

6. Bohleber W. The concept of intersubjectivity in psychoanalysis: taking critical stock. Int J Psychoanal. 2013;94:799-823.

7. Jones EE. Therapeutic action: a guide to psychoanalytic therapy. Northvale: Jason Aronson; 2000.

8. McAleavey AA, Castonguay LG. The process of change in psychotherapy: common and unique factors. In: Gelo OCG, Pritz A, Rieken B, editors. Psychotherapy research foundations, process, and outcome. Vienna: Springer; 2015. p. 293-310.
9. Ablon JS, Levy RA, Smith-Hansen L. The contributions of the Psychotherapy Process Q-Set to psychotherapy research. Res Psychother. 2011;14:14-48.

10. Goodman G, Athey-lloyd L. Interaction structures between a child and two therapists in the psychodynamic treatment of a child with Asperger's disorder. J Child Psychother. 2011;37:311-26.

11. Goodman G, Edwards K, Chung H. Interaction structures formed in the psychodynamic therapy of five patients with borderline personality disorder in crisis. Psychol Psychother. 2014;87:1531.

12. Ramires VRR, Carvalho C, Schmidt FMD, Fiorini GP, Goodman $\mathrm{G}$. Interaction structures in the psychodynamic therapy of a boy diagnosed with Asperger's Disorder: a single-case study. Res Psychother Psychopathol Process Outcome. 2015;18:129-40.

13. Goodman G. Interaction structures between a child and two therapists in the psychodynamic treatment of a child with borderline personality disorder. J Child Psychother. 2015;4:14161.

14. Serralta FB. Uncovering interaction structures in a brief psychodynamic psychotherapy. Paideia. 2016;26:255-63.

15. American Psychiatric Association. Diagnostic and Statistical Manual of Mental Disorders, 5th Edition (DSM-5). Washington: APA; 2013.

16. Eldar S, Gómez AF, Hofmann SG. Psychopathology and classification. In: Hofmann SG, editor. International perspectives on psychotherapy. Cham: Springer; 2017. p. 1-33.

17. Luyten $P$, Van Houdenhove $B$, Lemma A, Target M, Fonagy $P$. Vulnerability for functional somatic disorders: a contemporary psychodynamic approach. J Psychother Integr. 2013;23:250-62.

18. Marty $\mathrm{P}, \mathrm{M}^{\prime} \mathrm{Uzan} \mathrm{M}$ de. O pensamento operatório. Rev Bras Psicanal. 1994;28:165-74.

19. Aisenstein M. Soma and psyche: an indissociable unity. Int Congr. 2006;1286:183-8.

20. Ablon JS, Jones E. On analytic process. J Am Psychoanal Assoc. 2005;53:541-68.

21. Serralta $F B$, Nunes MLT, Eizirik CL. Elaboração da versão em português do Psychotherapy Process Q-Set. Rev Psiquiatr do Rio Gd do Sul. 2007;29:44-55.

22. Serralta $F B$, Pole $N$, Lucia M, Nunes $T$, Eizirik $C L$, Olsen $C$. The process of change in brief psychotherapy: effects of psychodynamic and cognitive-behavioral prototypes. Psychother Res. 2010;20:564-75.

23. Lambert M, Burlingame $G$, Umphress $V$, Hansen $N$, Vermeersch $D$, Clouse $G$, et al. The reliability and validity of the Outcome Questionnaire. Clin Psychol Psychother. 1996;3:249-58.

24. Lambert MJ, Gregersen AT, Burlingame GM. The Outcome Questionnaire. In: Maruish ME, editor. The use of psychological testing for treatment planning and outcome assessment:instruments for adults. Mahwah: Lawrence Erlbaum; 2004. p. 191-234.

25. Carvalho LDF, Rocha GMA. Tradução e adaptação cultural do Outcome Questionnaire (OQ-45) para o Brasil. Psico-USF. 2009;14:309-16.

26. Silva SM da, Alves ICB, Peixoto EM, Rocha GMA, Nakano T de C. Outcome Questionnaire (OQ-45.2): assessment of the psychometric properties using bifactor model and IRT. Psico. 2016;47:298-308.

27. Erkic M, Bailer J, Fenske SC, Schmidt SNL, Trojan J, Schröder A, et al. Impaired emotion processing and a reduction in trust in patients with somatic symptom disorder. Clin Psychol Psychother. 2018;25:163-72.

28. Shedler J. The efficacy of psychodynamic psychotherapy. Am Psychol. 2010;65:98-109.

29. Hardy GE, Llewelyn S. Introduction to psychotherapy process research. In: Gelo OCG, Pritz A, Rieken B, editors. Psychotherapy research: foundations, process, and outcome. Vienna: Springer; 2015. p. $183-94$.

\section{Correspondence:}

Pricilla Braga Laskoski

Universidade Federal do Rio Grande do Sul (UFRGS)

Av. Ramiro Barcelos, 2350

90035-903 - Porto Alegre, RS - Brazil

Tel. : +55 (51) 33085624

E-mail: pricillab@hotmail.com 